\title{
Characterization of Carbon Nanotube Based Polymer Composites Through Rheology
}

\author{
Robert Olejnik $^{\mathrm{a}}$, Pengbo Liu ${ }^{\mathrm{a}, \mathrm{b}}$, Petr Slobodian ${ }^{\mathrm{a}}$, Martin Zatloukal ${ }^{\mathrm{a}}$ and \\ Petr Saha ${ }^{\mathrm{a}}$
}

\author{
${ }^{a}$ Tomas Bata University in Zlín, Faculty of Technology, T.G.M. 275, 76272 Zlín, Czech Republic \\ ${ }^{b}$ Sichuan University, State Key Laboratory of Polymer Materials Engineering of China
}

\begin{abstract}
Poly(methyl methacrylate)/Multi-wall carbon nanotubes (MWCNT) nanocomposites were prepared by solution method. Here the dispersions of MWCNT in PMMA solutions were sonicated for appropriate time followed by dispersions coagulation. Both types of CNT materials were used such as pure MWCNT and the same MWCNT after their adequate surface treatment. The aim of treatment was to covalently attach organic material onto surface of CNT to process their better dispersion in polymeric matrix leading to more effective CNT reinforcement effect. The state of CNT dispersion was characterized thought rheology measurements with help of parameters like elasticity and viscosity of the melt. Also the effect of sonication onto pure PMMA matrix was determined.
\end{abstract}

Keywords: Carbon nanotubes, Polymer composites, Rheology.

PACS: 81.05.Qk, 81.05.Tp

\section{INTRODUCTION}

Carbon nanotubes (CNT) can be considered as very promising filler for polymeric matrixes. It is mainly due to their very high Young modulus reaching values of about $1 \mathrm{TPa}$ together with very high aspect ratio up to $10^{3}-10^{4}$, the promising is also their excellent electrical and thermal conductivity $[1,2]$. Unfortunately, fundamental problems still exist which disturb effective use of polymer/CNT nanocomposites. Particularly, it is very problematic to disperse CNT uniformly thought polymer matrix and practically avoid particles agglomeration creating carbon objects on micrometric scale $[3,4]$. Thus, it is very difficult to de-agglomerate the bundles or ropes (in the case of MWCNT [5] or SWCNT [6], respectively) using conventional methods of melt processing. Practically, in the nanocomposites prepared by convectional melt mixing methods agglomerates of nanotubes of micrometric size or larger can be observed in the matrix, e.g. PP [7], PMMA [4], HDPE [8, 9] or PA6 [10]. The aggregates of CNT considerably reduce the aspect ratio of the tubes, and thus the reinforcing effect. Also load transfer can be limited because of the bundles of nanotubes; when some of the tubes are not bonded to the matrix, they slip within the bundles, and it is easier for them to slide out of the bundle 
than to break $[11,12]$. Therefore the development and innovation of CNT/polymeric nanocomposites preparation methods is still a current issue. Commonly used methods, such as mixing in the polymeric melt, are being replaced by more efficient methods using e.g. ultrasound as a stirring element. Other efficient way to improve CNT dispersion in the polymeric matrix is chemical or chemical-physical modification (functionalization) of the CNT surface. The non-covalent method represents for example microemulsion polymerization technique in the presence of CNT material when polymeric material in the form of nanospheres is adsorbed onto the surface of CNT [13, 14]. Chemical functionalisation of CNT then represents creation of covalent bonds between organic molecules or polymeric fragments and CNT surface. Probably the most progressive method seems to be the process of CNT oxidation $[8,9]$ leading to creation of carboxyl and hydroxyls groups which become a binding element for different polymeric molecules $[15,16]$. The state of CNT dispersion and interaction between CNT and polymer matrix can be powerfully analyzed thought rheology measurements [17-19]. It is relatively easy and prompt indirect method.

\section{EXPERIMENTAL AND RESULTS}

At the first step MWCNT (Sun Nanotech Co. Ltd., China, diameter 10-30 nm, length 1-10 $\mu \mathrm{m}$, purity $<90 \%$ ) were oxidized in mixture of sulfuric and nitric acids [20]. In the next step 4,4'-methylenebis(phenyl isocyanate) (MDI) and methacrylamide were used to synthesize so called "CNT-mer" [21] forming active polymerizable vinyl groups on CNT surface which are able to incorporate CNT into growing PMMA polymer chain during consequential radical solution polymerization.

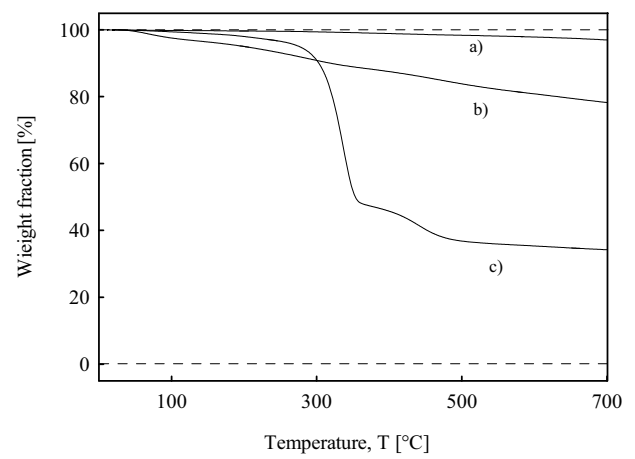

FIGURE 1. Thermogravimetric analysis of as-received MWCNT (a) oxidized MWCNT (b) and MWCNT grafted by the MDI binding agent and PMMA (c).

Figure 1 shows TG analyses of such chemical treatment. Part a) represents pure MWCNT material and part b) after its oxidation. In part c) two decomposition events can 
be observed. The first represent the decomposition of binding material (MDI) and the second of PMMA polymer chains covalently bonded onto CNT surface. The total content of organic material is about 65 wt. \%. Additional HRTEM analyses (Figure 2) demonstrates the presence of organic film on the surface of MWCNT.

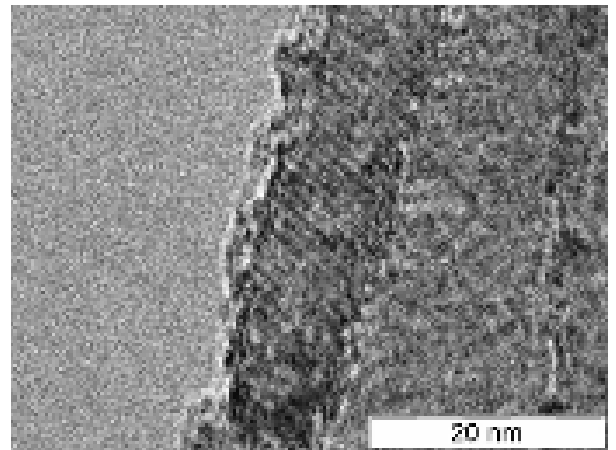

FIGURE 2. TEM morphology of MWCNT surface treated tube. The image shows one wall of MWCNT tube assembled from $\sim 25$ of individual graphitic layers with distance between particular layer $\sim 0.35 \mathrm{~nm}$ covered by grafted organic layer with thickness $\sim 3.5 \mathrm{~nm}$.

Prepared surface treated filler was separated by ultracentrifugation and finally mixed into PMMA commercial polymer (DELPET 80N, Asahi Kasei Corporation) by solution method as was announced above. The CNT dispersion in methylethyl ketone (MEK) with concentration from $0.1,0.5,1.0$ to $2.0 \mathrm{wt} . \%$ of $\mathrm{CNT}$ were prepared by sonication using thermostatic ultrasonic bath (Bandelin electronic DT $103 \mathrm{H}$ ) at $70^{\circ} \mathrm{C}$ for 4 or 8 hours followed by additional 2 hours using ultrasonic homogenized (Dr. Hielscher $\mathrm{GmbH}$ apparatus with ultrasonic horn, S7) at $60^{\circ} \mathrm{C}$. The coagulation was performed by pouring of prepared dispersions into mixer filled by antisolvent - water.

The states of prepared composites were characterized thought rheology measurements using the Advanced Rheometric Expansion System (ARES 2000) Rheometrics rheometer in terms of complex viscosity and recoverable shear. In the first step, the effect of sonication time on the complex viscosity of PMMA has been investigated (see Figure 3). It is clearly visible that increase in the sonication time leads to decrease in complex viscosity which can be taken as evidence that the PMMA degradates during the sonication process. In the second step, the effect of CNT content in the PMMA melt on its elasticity (recoverable shear) has been investigated (see Figure 4). Obviously, the increase in the CNT level in the PMMA matrix leads to increase in the PMMA melt elasticity. Finally, the effect of the CNT surface modification, which is described above, on the PMMA melt elasticity has been analyzed through recoverable shear (see Figure 5). In this case, the surface modified CNT in the PMMA matrix enhances the melt elasticity more than no surface modified CNT which suggest that the suggested CNT surface modification might be good tool to improve the interaction between CNT and PMMA polymer matrix. 


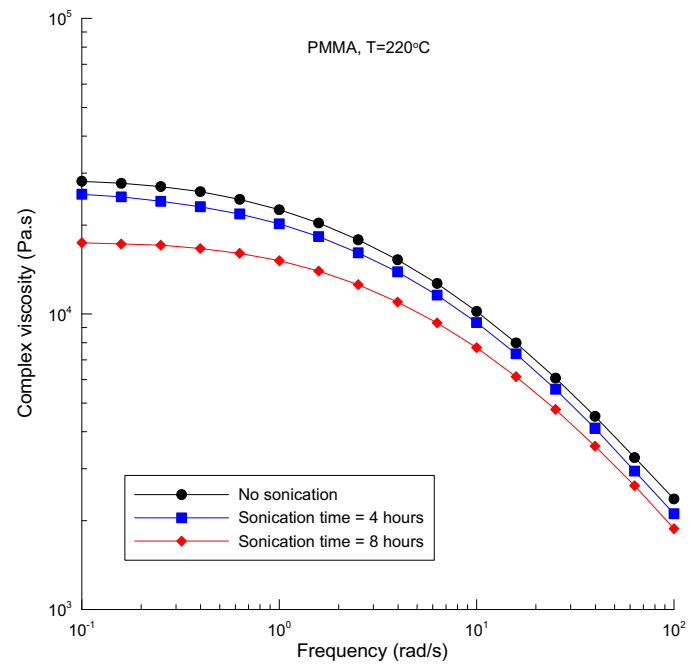

FIGURE 3. Effect of the sonication time on the frequency dependent complex viscosity for PMMA polymer melt.

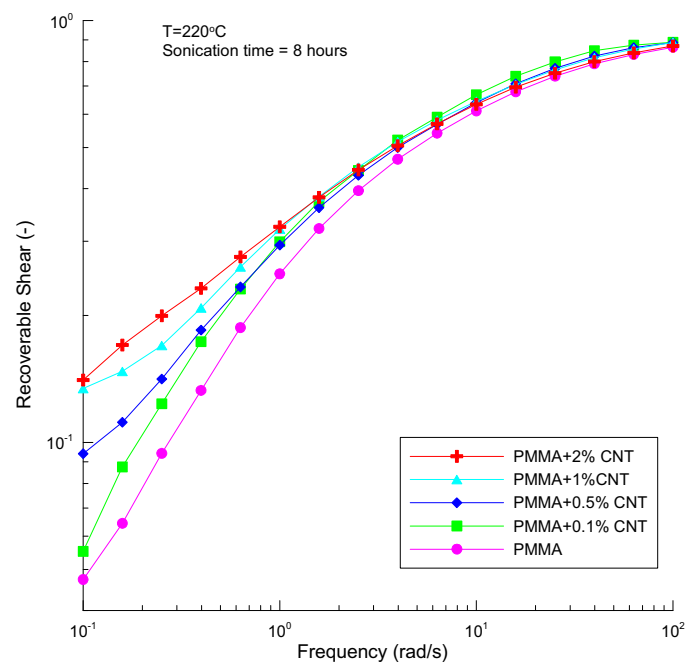

FIGURE 4. Effect of the CNT content in the PMMA melt on the recoverable shear. 


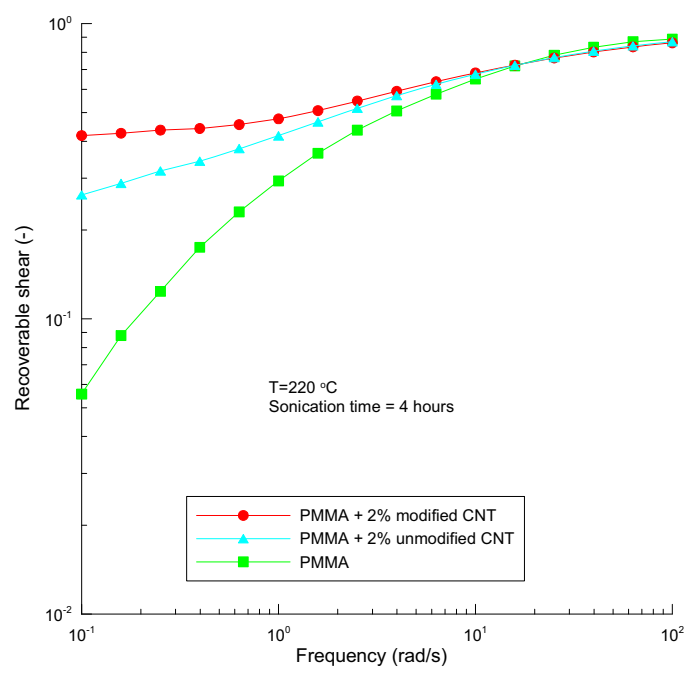

FIGURE 5. Effect of the CNT surface modification on the recoverable shear for CNT+PMMA composite.

\section{CONCLUSION}

Based on the rheological evaluation of the tested polymer samples, it has been found that, firstly, sonication of the PMMA can leads to degradation. Secondly, the increase of the CNT content in the CNT+PMMA may leads to enhanced melt elasticity and finally, modification of the CNT surface can increase the CNT+PMMA melt elasticity more than surface no modified CNT.

\section{ACKNOWLEDGMENTS}

The financial support by project MSM 7088352101 is gratefully acknowledged.

\section{REFERENCES}

1. I. Szleifer, R. Yerushalmi-Rozen, Polymer 46, 7803 (2005).

2. X. L. Xie, Y. W. Mai and X. P. Zhou, Mat. Sci. Eng. R 49(4), 89 (2005).

3. H. T. Ham, Y. S. Choi and I. J. Chung, J. Colloid Interf. Sci. 286 (1), 216 (2005).

4. P. Slobodian, A. Lengálová, M. Šlouf and P. Sáha, J Reinf Plast Comp 26, 1705 (2007).

5. H. Kathyayini, I. Willems, A. Fonseca, J. B. Nagy, N. Nagaraju, Catal. Commun. 3, 140 (2006). 
6. A. Thess, R. Lee, P. Nikolaev, H. J Dai and P. Petit, et. al, Science 273, 483 (1996).

7. M. A. L. Manchado, L. Valentini, J. Biagiotti and J. M. Kenny, Carbon 43, 1499 (2005).

8. Q. H. Zhang, S. Rastogi, D. J. Chen, D. Lippits and P. J. Lemstra, Carbon 44, 778 (2006).

9. W. Z. Tang, M. H. Santare and S. G. Advani, Carbon 41, 2779 (2003).

10 D. Meincke, H. Kaempfer, C. Weickmann, M. Friedrich, et. al, Polymer 45, 739 (2004).

11. P. M. Ajayan, L. S. Schadler, C. Giannaris and A. Rubio, Advanced Materials 12, 750 (2000).

12. L. S. Schadler, S. C. Giannaris and P. M. Ajayan, Applied Physics Letters 73, 3842 (1998).

13. H. T. Ham, Y. S. Choi, M. G. Chee and I. J. Chung, J Polym Sci Pol Phys 44, 573 (2006).

14. C. S. Chern and L. J. Wu, J Polym Sci Pol Chem 39, 3199 (2001).

15. T. Ramanathan, H. Liu and L. C. Brinson, J. Polym. Sci.: Part B-Polym. Phys. 43, 3269 (2005).

16. T. Ramanathan, F. T. Fisher, R. S. Ruoff and L. C. Brinson, Chemistry of Materials 17, 1290 (2005).

17. K. Zhang, J. Y. Lim and H. J. Choi , Diam Relat Mater 18 (2-3) 316 (2009).

18. M. P. Lalko, L. Rakesh and S. Hirschi, J Therm Anal Calorim 95(1) 203 (2009).

19. F. M. Du , R. C. Scogna, W. Zhou, S. Brand, J. E. Fischer and K. I. Winey, Macromolecules 37, 9048 (2004).

20. A. Rasheed, J. Y. Howe, M. D. Dadmun and P. F. Britt, Carbon 45, 1072 (2007).

21. J. U. Ha, M. Kim, J. Lee, S. Choe, I. W. Cheong and S.E. Shim, J Polym Sci Part A-Polym Chem 44, 6394 (2006). 
Copyright of AIP Conference Proceedings is the property of American Institute of Physics and its content may not be copied or emailed to multiple sites or posted to a listserv without the copyright holder's express written permission. However, users may print, download, or email articles for individual use. 